\title{
Under graduate student feedback on teaching and evaluation method in clinical pharmacology
}

\section{${ }^{1}$ Deo SK}

${ }^{1}$ Lecturer, Department of Pharmacology, Institute of Medicine, TUTH, Mahrajgunj Kathmandu, Nepal

\section{ABSTRACT \\ Background}

Any teaching and evaluation method can be considered as effective once they are judged by students.

\section{Objective}

This study was designed to obtain feedback on teaching and evaluation methods in the subject of clinical pharmacology among under graduate students

\section{Methods}

Feedback on teaching and evaluation method was taken from undergraduate students of 2009 batch and various approaches to teaching and evaluation are identified. To know the effect of these novel approaches of teaching and evaluation, student feedback was taken from subsequent batch 2010 and 2011 using a written validated questionnaire covering various aspects of teaching and evaluation methods.

\section{Results}

Under graduate students were satisfied with all teaching methods like lecture and pharmacological exercises. They showed preference for tutorials, short answer questions and revision classes where as they were not satisfied with seminar method of learning.

All students felt that there should be more time for clinical pharmacology and pharmacological problem based exercises.. The pass percentage of the subsequent batch in university examinations improved from $75 \%$ to $90 \%$.

\section{Conclusion}

Based upon the student's feedback, incorporation of suggestion obtained from the students resulted in improvement in performance of the students. Hence, it is very essential to take regular feedback from the students to synchronize teaching and evaluation method of the students

\section{Key Words: Under graduate student teaching and evaluation, Pharmacology.}


Journal of College of Medical Sciences-Nepal, 2013, Vol-9, No-3,

\section{INTRODUCTION}

It is very essential while educating under graduate students in clinical pharmacology and therapeutics that to ensure an effective and safe drug therapy. Prescribing drugs is an integral part of medicine and good knowledge of clinical pharmacology is back bone to rational drug therapy.Pharmacology involving many drugs and its knowledge including mechanisms of drug action and even the diseases for which the various drugs are used. ${ }^{1}$ Generally the undergraduate students' neglects pharmacology and think of it as more difficult learning area than other subjects. Hence teaching pharmacology has been a challenge.So education of pharmacology needs to be radically reformed to contribute to better professional clinical services.

However, the pharmacology curriculum has shifted much toward clinical pharmacology in last few years in undergraduate teaching in Nepal. There are various attempts in all three universities of Nepal to make the teaching of pharmacology more interesting and relevant. $^{2}$ One of the course assessment techniques like student feedback may help to know about the advantage and limitation of teaching and assessment methods. ${ }^{3,4}$ Currently, student's feedback represents the primary means used by most programs to assess their methodology. ${ }^{5}$ This stimulated us to undertake this study to evaluate the teaching and assessment in pharmacology for undergraduate medical students.

\section{METHODS}

The study was conducted at the Department of Clinical Pharmacology of Kantipur Dental College and Research Center, Bashundhra, Kathmandu, among the students of second year.
Based upon an earlier feedback, we tried to emphasize more on clinical pharmacology than the simple textbook knowledge and pharmacy exercises. A structured validated questionnaire was developed that consisted of 10 questions with four options. Students $(n=80)$ were also allowed to offer their own suggestions/remarks. The obtained data analyzed and the frequency of different statements and then agreed on a common consensus

A total number of $96 \%$ of the questionnaires were found to be sufficient for data analysis. Tutorials, demonstrations, Computer simulation and revision classes were rated as good or very good by most of the students (Figure : 1 )

\section{RESULT}

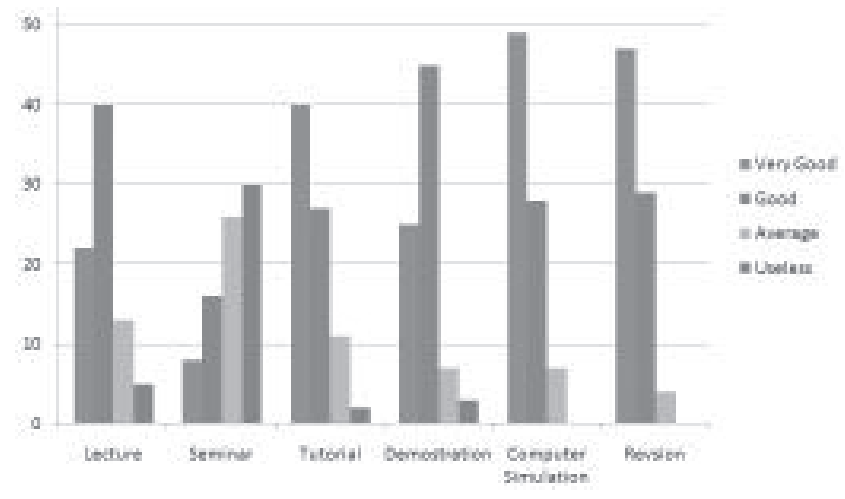

Fig No 1: Showing different teaching methods and response by students.

Students found revision classes held at the end of the course to be the best form of teaching (94\%) followed by practical demonstrations and the practical work done by the students themselves (87.5\%). Most of the students rated useless or average for seminar method of learning.(70\%). Students expressed lecture 
Deo SK. et al. under graduate student.

method of learning is less effective as compare to other learning method $(22.5 \%)$.

In assessment methodology, pre-university tests held at the end of course were found to be most useful (92.5 $\%$ ) in preparing for final university examination followed by class tests (86.25\%), revision tests (87.25\%), mock viva just before exam (78.75\%), and revision of the old question paper (76.25).(Figure: 2 )

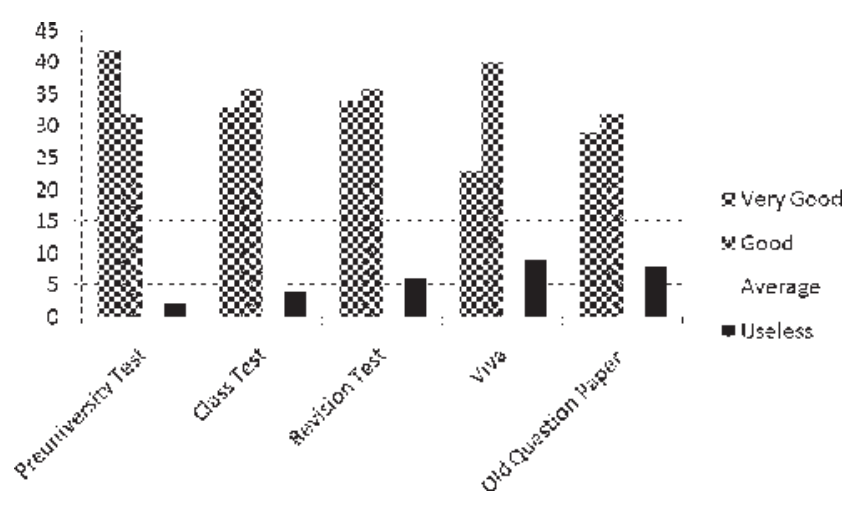

Fig No 2: Showing different assessment methodology and response by students.

The university examinations scores of the batch 2009 and 2010 in which we implemented innovative methods showed significant improvement as compared to earlier batch (2009). The pass percentage of batch 2010-11 was $90 \%$ as compared to $2009(75 \%)$. The average marks in pharmacology increased significantly by $9 \%$ in 2010 and 2011.

\section{DISCUSSION}

Students are satisfied with tutorials method of learning and requested for more regular tutorials classes. They also suggested that only 15-20 students should be kept in one group instead of 25 students. Although students feels demonstration method of learning is interactive and able to understand clinical pharmacology in broader sense but students further added that pharmacy exercises should be decreased and should be restricted to clinical pharmacology only. Computer simulation classes showed good satisfaction (96\%) among all the students. Students also expressed that animals should not be sacrificed for experiments and computer simulation models may be used instead. Students (94\%) found revision classes held at the end of the courses beneficial and claims able to recall everything what has been taught throughout the year. This further improves confidence in the subject. Students found seminars to be an average or no utility. This could be because they need to put in efforts to prepare for these. They also emphasized that lectures should be more interactive.

Pre-university test conducted before board exam is very effective in final university examination. Students feel they are able to access themselves where they stand and develops more confidence for appearing for university examination. Student also expressed usefulness of regular class tests conducted after completion of each system. They believed that they are able to identify "must know" area in that system which further helped while preparing for exam. Similarly revision Test, mock viva, revision of the old question paper is equally useful while preparing for the exam. Mock viva is good drill for the students to appear for grand viva voce.

\section{CONCLUSION}

As pharmacology course is rapidly developing with various new drug discovery and better understanding of pharmacokinetic and pharmacodynamic aspects of drugs hence it is vital to know the needs of the student and whether they are able to cope of with ever- 
Journal of College of Medical Sciences-Nepal, 2013, Vol-9, No-3, expanding course in the limited duration of time.So practical sessions. Journal of Educational frequent feedbacks which may help teachers to plan Evaluation for Health Professions. 2011; 8: 12 the curriculum that further helps to improve upon the teaching and assessment methods.

3. Badyal.DK, Bala.S, Kathuria.P, Student evaluation of teaching assessment methods in pharmacology

\section{REFERENCES}

1. Wang. J, Hu.X, Xi.J. Cooperative learning with role play in Chinese pharmacology education. Indian Journal of Pharmacology. 2012; 44(2): 253-256

4. Richardson.BK, Feedback. Acad Emerg Med 2004;11:e1-5.

5. Kaur.N, Gupta. A, Saini.P, A needs assessment study of undergraduate surgical education. National Medical Journal of India. 2011; 24(5): 292-293

2. P.R. Shankar et.al Feedback on and knowledge, attitude, and skills at the end of pharmacology 